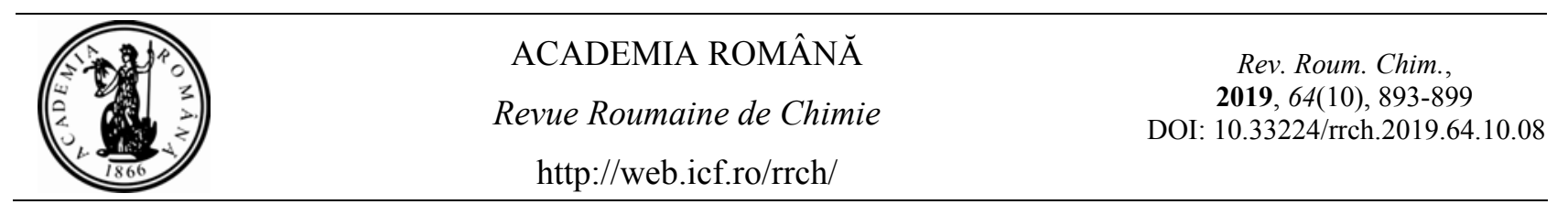

\title{
THERMAL DEGRADATION OF ANTHOCYANIN PIGMENTS IN BILBERRY, BLACKBERRY AND BLACK MULBERRY EXTRACTS IN THE PRESENCE OF SOME ADDED FOOD ANTIOXIDANTS
}

\author{
Adina CĂTA, ${ }^{a,{ }^{*}}$ Ioana M.C. IENAŞCU, ${ }^{\mathrm{a}, \mathrm{b}}$ Cristian TĂNASIE ${ }^{\mathrm{a}}$, and Mariana N. ŞTEFĂNUȚ ${ }^{\mathrm{a}}$ \\ ${ }^{a}$ National Institute of Research and Development for Electrochemistry and Condensed Matter, \\ Dr. Aurel Păunescu Podeanu 144, 300569, Timişoara, Roumania \\ b،Vasile Goldiş" Western University of Arad, Faculty of Pharmacy, Liviu Rebreanu 86, 310045, Arad, Roumania
}

Received November 1, 2018

\begin{abstract}
Anthocyanins, the broadest group of water-soluble pigments in plants, present a special importance in terms of high potential for their use as natural colorants due to easy incorporation in aqueous media, but also for their nutritional qualities and beneficial effects on health, especially due to their antioxidant effects. A limiting factor for anthocyanins incorporation in food is low stability of these pigments under the influence of various factors, one of the most important being temperature. In this study, the stability of ethanolic anthocyanin extracts from wild bilberry, blackberry and black mulberry with and without added ascorbic acid and butylated hydroxyanisole was investigated. The variations in anthocyanins content and antioxidant activity during storage for 2 weeks at $60^{\circ} \mathrm{C}$ and 4 months at room temperature were

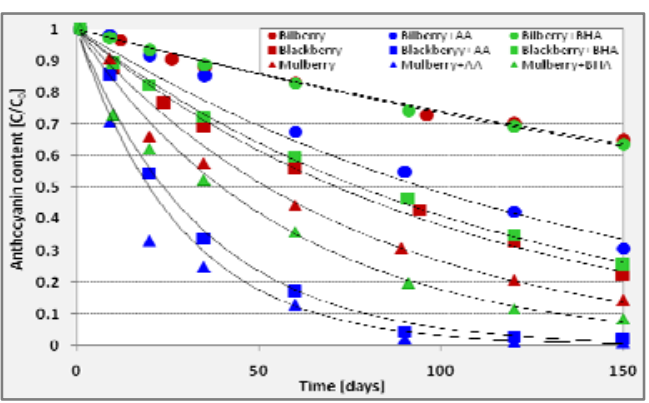
determined. Total monomeric anthocyanins content was quantified by using a $\mathrm{pH}$ differential method and antioxidant activity evaluation was performed by using FRAP (ferric reducing/antioxidant capacity) assay. The obtained results indicate that the anthocyanins degradation followed first-order reaction kinetics. A very fast degradation occurred at high temperature. During storage at room temperature, anthocyanins showed a better stability. The untreated extracts present a good stability. Generally, the extracts treated with ascorbic acid present a faster degradation.
\end{abstract}

\section{INTRODUCTION}

Anthocyanins are a class of natural pigments with a paramount importance both as water-soluble natural colorants and high nutritional properties. The increased interest on the anthocyanins investigation has been generated by the legislative limitation concerning the use of synthetic dyes in food products. Also, the consumers become increasingly concerned about adverse health effects of synthetic colorants, which led to a greater involvement of food producers to attempt to use anthocyanins as substitute for E129 (Allura red), the most widely used synthetic colorant. ${ }^{1}$ In
EU, anthocyanin-derived natural colorants are recognized under classification E163. ${ }^{2}$

Furthermore, anthocyanins are regarded as important nutraceuticals mainly due to their antioxidant effect, which gives them a potential role in prevention of various diseases associated with oxidative stress such as cancer, ${ }^{3}$ diabetes ${ }^{4,5}$ or cardiovascular diseases. ${ }^{6,7}$

Unfortunately, the practical applicability of anthocyanins is limited due to their low stability under the influence of various factors: $\mathrm{pH}$, storage temperature, presence of enzymes, chemical structure, light, oxygen, solvents, the presence of other compounds, etc. ${ }^{8}$

\footnotetext{
* Corresponding author: adina.cata@yahoo.com
} 
Anthocyanins degradation may occur during extraction, purification, processing or storage which can have a deeply impact on colour quality and may also affect nutritional properties. Temperature is the second crucial parameter affecting the anthocyanins stability. Thermal processing of foods involves heating to temperatures in the range of 50 to $150^{\circ} \mathrm{C}$, depending upon $\mathrm{pH}$ of the product and desired shelf life. ${ }^{9}$

Antioxidants are regularly added to food products such as juices or other fruit preparations in order to protect them against oxidation and increase their shelf-life. The most frequently used chemical antioxidants for food and pharmacological applications are phenolic compounds such as butylated hydroxyanisole (BHA), butylated hydroxytoluene (BHT), tertbutylhydroquinone (TBHQ) and propyl gallate (PG). ${ }^{10,11}$ Also, ascorbic acid (vitamin C) is one of the most common antioxidant used as food additive. It occurs naturally in many fruit and vegetables and can also be manufactured synthetically. Ascorbic acid is effective in scavenging the superoxide radical anion, hydrogen peroxide, hydroxyl radical, singlet oxygen and reactive nitrogen oxide. ${ }^{12}$

The objective of this study was to evaluate the stability of anthocyanin extracts from wild bilberry, blackberry and black mulberry with and without added ascorbic acid (AA) and butylated hydroxyanisole (BHA) during storage at room temperature and $60^{\circ} \mathrm{C}$. The variations in anthocyanins content and antioxidant activity were followed during storage. Kinetic parameters for thermal degradation of anthocyanins such as degradation rate constant $(k)$ and half-life time $\left(t_{1 / 2}\right)$ were determined.

\section{MATERIALS AND METHODS}

\section{Materials}

6-hydroxy-2,5,7,8-tetramethylchromane-2-carboxylic acid 97\% (Trolox), Iron (III) chloride, 2,4,6-tris(2-pyridyl-1,3,5-triazine) (TPTZ), L-ascorbic acid, 2(3)-tert-butyl-4-hydroxyanisole and ethanol were purchased from Sigma-Aldrich, Germany. Hydrochloric acid was obtained from Merck, Germany. Black mulberry (Morus nigra L.), blackberry (Rubus fruticosus L.) and bilberry (Vaccinium myrtillus L.) were harvested from south-western Roumania (Caraş-Severin) at the maturity stage and were kept at $-18^{\circ} \mathrm{C}$ until the sample preparation.

\section{Samples preparation}

Anthocyanins extraction was carried out in ethanol acidified with $0.1 \% \mathrm{HCl}$, at solid to solvent ratio $1: 4(\mathrm{w} / \mathrm{v})$ in ultrasonic conditions at $59 \mathrm{kHz}$ (ultrasonic bath FALC Instruments - Italy) and $25^{\circ} \mathrm{C}$ for 60 minutes. After filtration through a Whatman no. 1 filter paper, the extracts have been concentrated in a rotary evaporator (Laborota 4000 Efficient, Heidolph, Germany) at $35-40^{\circ} \mathrm{C}$ under vacuum (40-45 mbar). For degradation experiments, each extract was divided in three parts, one part remains untreated, second part was mixed with ascorbic acid (AA) and the third part was mixed with butylated hydroxyanisole (BHA) in order to obtain $1 \%$ concentration in fruits extracts.

\section{Degradation studies}

The stability of anthocyanins was studied during 150 days at room temperature in the dark and 2 weeks at $60^{\circ} \mathrm{C}$. The extracts were introduced into test tubes well capped to avoid evaporation and placed in a drying chamber with digital adjustment of temperature. At regular time intervals, the tubes with sample were removed from the drying chamber and rapidly cooled into an ice-water bath to stop thermal degradation. The changes in anthocyanin content and antioxidant activity of the extracts have been monitored during storage at both temperatures.

\section{Quantification of anthocyanins content}

Total monomeric anthocyanins content was quantified according to the $\mathrm{pH}$ differential method described by Giusti and Wrolstad. ${ }^{13}$ The samples were properly diluted in $\mathrm{pH} 1.0$ and $\mathrm{pH} 4.5$ buffers, then the absorbances at $\lambda_{\text {vis-max }}$ and $700 \mathrm{~nm}$ were read at room temperature. A Jasco V $530 \mathrm{UV}$-Vis spectrophotometer was used for measurements. Pigment content was expressed as cyaniding-3glucoside equivalents ( $M W=449.2$ and $\varepsilon=26900$ ). Each sample was analyzed in triplicate and the results were expressed as the averages of the two measurements.

\section{Antioxidant activity}

Antioxidant activity evaluation was performed by using FRAP (ferric reducing/antioxidant capacity) assay according to Benzie \& $\operatorname{Strain}^{14}$ with some modification. The fresh FRAP solution was prepared by mixing $300 \mathrm{mmol} / \mathrm{L}$ acetate buffer 
$(\mathrm{pH}=3.6)$ with $10 \mathrm{mmol} / \mathrm{L}$ TPTZ (2,4,6-tripyridyltriazine) in $40 \mathrm{mmol} / \mathrm{L} \mathrm{HCl}$ and $20 \mathrm{mmol} / \mathrm{L}$ $\mathrm{FeCl}_{3} \cdot 6 \mathrm{H}_{2} \mathrm{O}$ solution in a volumetric ratio of 10:1:1. The resulting solution was diluted with 2 volumes of dd water and was incubated at $37^{\circ} \mathrm{C}$ for 30 minutes. $2.9 \mathrm{~mL}$ of working FRAP solution were mixed with $100 \mu \mathrm{L}$ of extract (previously diluted 1:200 with alcohol) and was kept in dark for 2 hours, at room temperature. An intense blue colour is formed when the ferric-tripyridyl-triazine complex is reduced to ferrous form. The absorbance of the samples and a blank was measured at $593 \mathrm{~nm}$ against dd water using a Jasco V 530 UV-Vis spectrophotometer. The antioxidant reference compound used was Trolox. The calibration curve was obtained using standard solutions in the range 0.3-1.0 mmol/L Trolox. Each sample was analyzed in triplicate and the results were expressed as the averages of the two measurements.

\section{RESULTS AND DISCUSSION}

The variation of anthocyanin content in bilberry, blackberry and mulberry extracts with and without the addition of $\mathrm{AA}$ and $\mathrm{BHA}$ during storage is presented in Figures 1, 2 and 3.

The initial content of anthocyanins in bilberry samples was $11180 \pm 52 \mathrm{mg} / \mathrm{L}$ for untreated extract, $11011 \pm 37 \mathrm{mg} / \mathrm{L}$ for the extract with AA, and $10808 \pm 2 \mathrm{mg} / \mathrm{L}$ for the extract treated with BHA. After 150 days of storage at room temperature, the anthocyanin content in bilberry extracts decreases to $7271 \pm 46 \mathrm{mg} / \mathrm{L}$ for untreated extract, $3371 \pm 2 \mathrm{mg} / \mathrm{L}$ for the extract with $\mathrm{AA}$, and $6685 \pm 6 \mathrm{mg} / \mathrm{L}$ for the extract with BHA. During storage at $60^{\circ} \mathrm{C}$, a decrease in anthocyanin content of $96.5 \%$ for untreated extract, $98.4 \%$ for the extract with AA and $91.9 \%$ for the extract with BHA were observed after 2 weeks of storage.

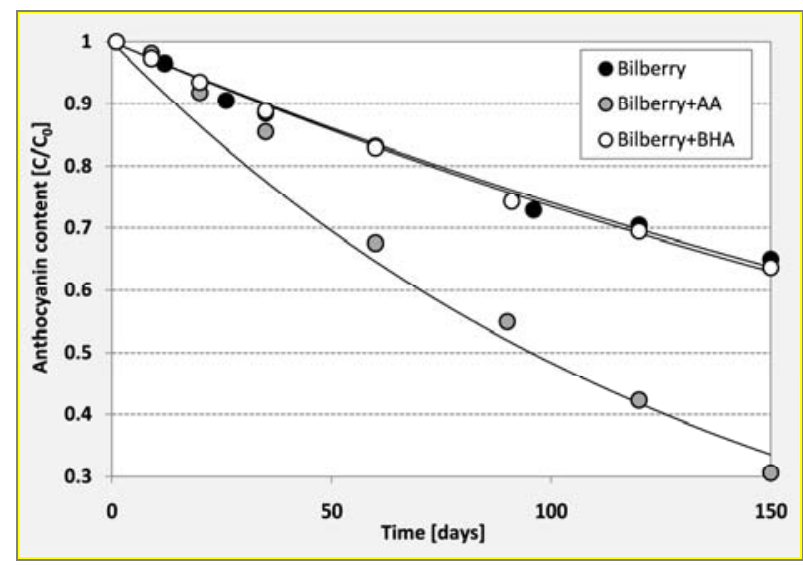

A.

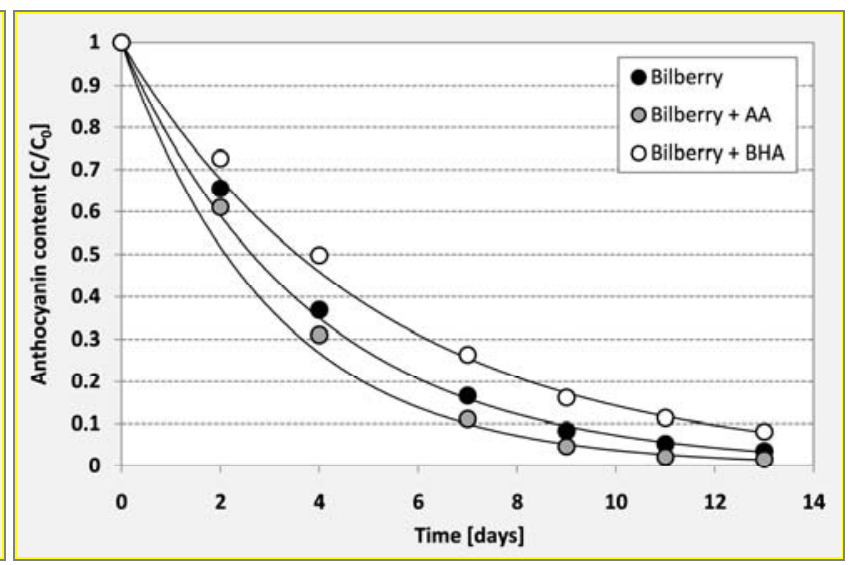

B.

Fig. 1 - Degradation of anthocyanins in bilberry extract during storage at room temperature $(\mathrm{A})$ and $60^{\circ} \mathrm{C}(\mathrm{B})$.

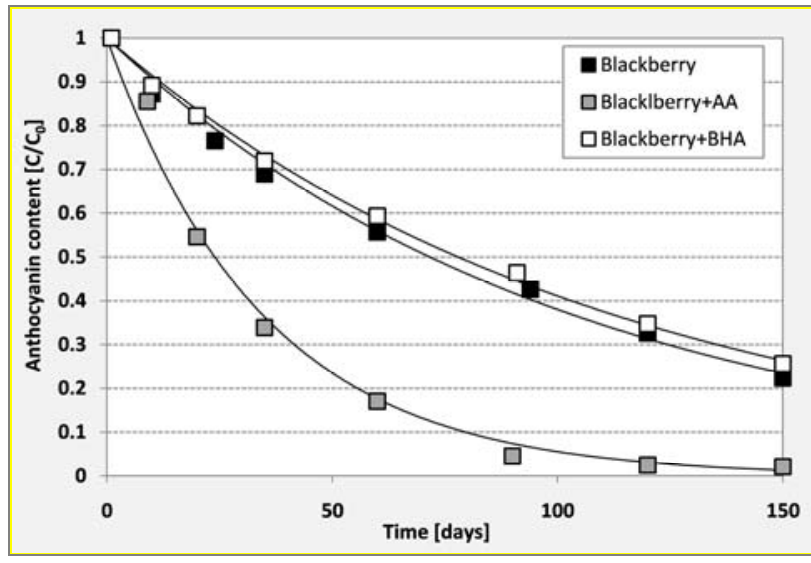

A.

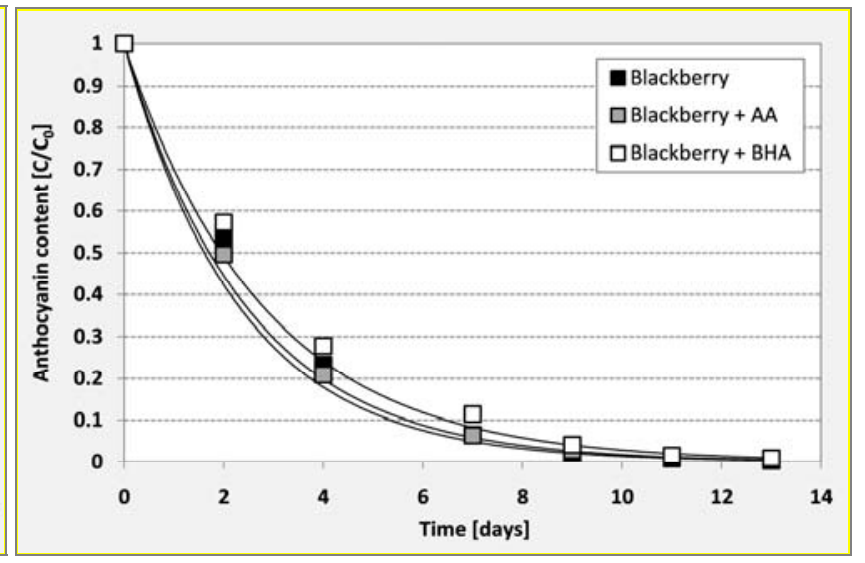

B.

Fig. 2 - Degradation of anthocyanins in blackberry extract during storage at room temperature (A) and $60^{\circ} \mathrm{C}(\mathrm{B})$. 


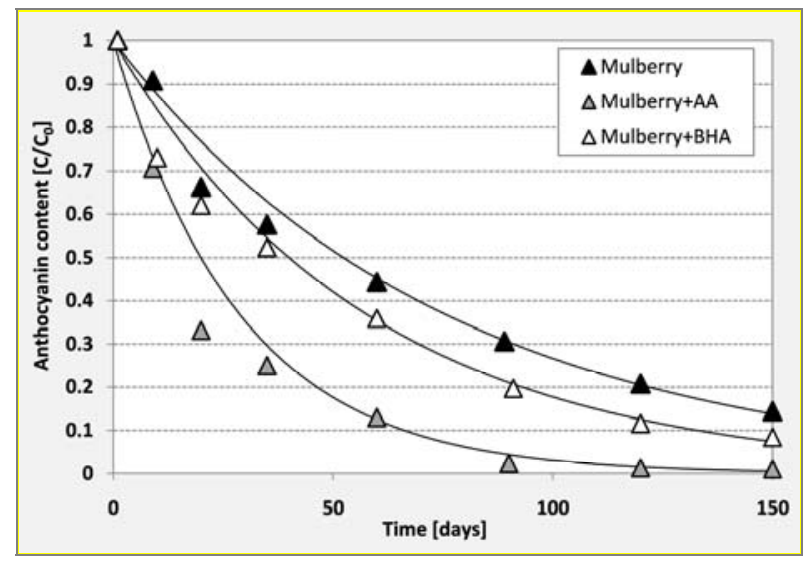

A.

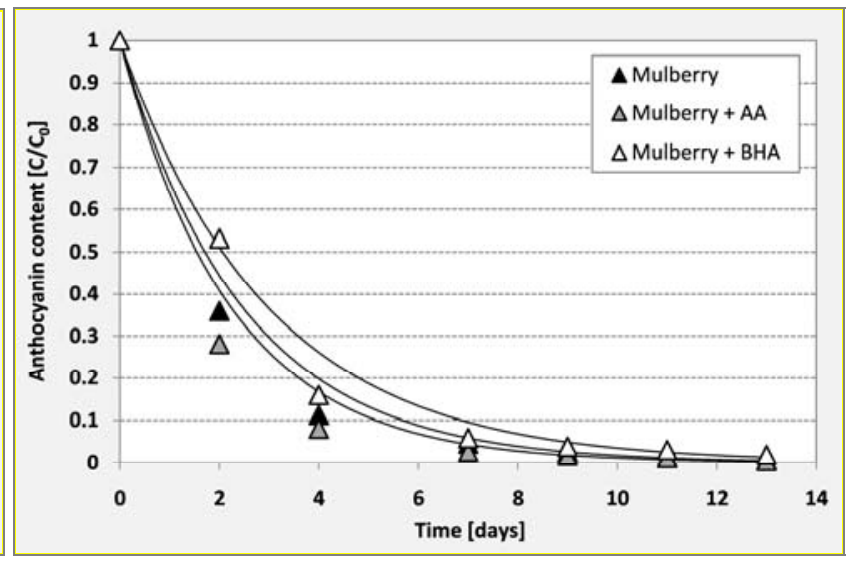

B.

Fig. 3 - Degradation of anthocyanins in mulberry extract during storage at room temperature (A) and $60^{\circ} \mathrm{C}(\mathrm{B})$.

In blackberry samples, anthocyanin content decreases from $5941 \pm 5 \mathrm{mg} / \mathrm{L}$ to $1328 \pm 5 \mathrm{mg} / \mathrm{L}$ for untreated extract, from $5900 \pm 29 \mathrm{mg} / \mathrm{L}$ to $127 \pm$ $1 \mathrm{mg} / \mathrm{L}$ for the extract with AA, and from $5827 \pm$ $16 \mathrm{mg} / \mathrm{L}$ to $1493 \pm 21 \mathrm{mg} / \mathrm{L}$ for the extract with BHA after 150 days of storage at room temperature. Anthocyanin content decreased significantly after 2 weeks of storage at $60^{\circ} \mathrm{C}$, the final levels of anthocyanin were $11.7 \pm 1.1 \mathrm{mg} / \mathrm{L}$ for untreated extract, $29.3 \pm 0.6 \mathrm{mg} / \mathrm{L}$ for the extract with AA, and $54.8 \pm 2.2 \mathrm{mg} / \mathrm{L}$ for the extract with BHA.

Anthocyanin content in mulberry samples stored at room temperature decreased from $5607 \pm 65 \mathrm{mg} / \mathrm{L}$ to $807 \pm 22 \mathrm{mg} / \mathrm{L}$ for untreated extract, from $5515 \pm$ $56 \mathrm{mg} / \mathrm{L}$ to $56 \pm 10 \mathrm{mg} / \mathrm{L}$ for the extract with $\mathrm{AA}$, and from $5562 \pm 77 \mathrm{mg} / \mathrm{L}$ to $468 \pm 8 \mathrm{mg} / \mathrm{L}$ for the extract with BHA. At $60^{\circ} \mathrm{C}$, the losses of anthocyanin pigments are higher, the content of anthocyanins after 2 weeks were $38.2 \pm 2.0 \mathrm{mg} / \mathrm{L}, 21.6 \pm 1.9 \mathrm{mg} / \mathrm{L}$ and $54.8 \pm 2.2 \mathrm{mg} / \mathrm{L}$, respectively.

The changes in antioxidant activities for each extract were also monitored during storage. The values are shown in Tables 1-3.

As expected, anthocyanin degradation increased with temperature and time in all cases. As can be clearly seen from the Figures 1-3, the addition of ascorbic acid had a negative influence on the anthocyanins concentration, leading to acceleration of their degradation during storage. Ascorbic acid is one of the most common antioxidant used as food additive but some studies have shown that the presence of ascorbic acid has a negative effect on anthocyanin stability. ${ }^{15-17}$ The addition of butylated hydroxyanisole was found to have no significant influence on anthocyanins concentrations for bilberry and blackberry extracts; for mulberry extract was observed a more pronounced negative effect (Figure 3). The addition of AA and BHA into fruits extracts increased the antioxidant activity (Tables 1-3). During storage, antioxidant activity show only a slight decrease compared with anthocyanins content.

Anthocyanins degradation during storage at both considered temperatures followed first-order reaction kinetics. In all cases, the $\mathrm{R}^{2}$ values were higher than 0.94 indicating a good data fit. Our results confirmed that anthocyanin degradation could be modeled by first-order reaction kinetics, in agreement with previous studies reporting the thermal degradation of anthocyanins from the same sources. ${ }^{18-20}$

The first-order reaction rate constant $(k)$ for each series of experiments was calculated using the following equation:

$$
C_{t}=C_{0} \cdot \exp (-k t)
$$

where $C_{0}$ is the initial monomeric anthocyanins concentration and $C_{\mathrm{t}}$ is the anthocyanins concentration after time $(t)$ of storage.

The half-lives (time necessary for $50 \%$ degradation of anthocyanins) were calculated by the following equation:

$$
t_{1 / 2}=-\ln 0.5 / k
$$

Kinetic parameters for thermal degradation of anthocyanins are summarized in Table 4 for the experiments performed at room temperature, and Table 5 for the experiments carried out at $60^{\circ} \mathrm{C}$. Comparison of the kinetic parameters clearly indicates that anthocyanins from bilberry extract are the most stable for long-term storage. The presence of ascorbic acid in the fruits extracts resulted in higher degradation rates and a dramatic reduction of half-lives of anthocyanin for samples stored at room temperature. 
Table 1

Antioxidant activity of bilberry extract during storage

\begin{tabular}{cccc}
\hline \multirow{2}{*}{$\begin{array}{c}\text { Time } \\
\text { [days] }\end{array}$} & Bilberry & Bilberry + AA & Bilberry + BHA \\
\cline { 2 - 4 } & Storage at room temperature & & \\
1 & $192.75 \pm 10.78$ & $269.55 \pm 7.55$ & $262.61 \pm 0.89$ \\
12 & $191.93 \pm 2.47$ & $264.54 \pm 6.59$ & $252.97 \pm 7.60$ \\
26 & $191.09 \pm 3.69$ & $260.24 \pm 4.14$ & $250.38 \pm 1.19$ \\
35 & $190.82 \pm 3.65$ & $251.21 \pm 4.24$ & $251.25 \pm 1.36$ \\
60 & $185.77 \pm 3.99$ & $234.74 \pm 5.41$ & $246.12 \pm 0.62$ \\
96 & $178.34 \pm 2.68$ & $220.91 \pm 1.81$ & $244.28 \pm 4.20$ \\
120 & $174.21 \pm 1.21$ & $208.56 \pm 3.37$ & $239.55 \pm 0.22$ \\
150 & $174.11 \pm 1.93$ & $202.95 \pm 1.66$ & $232.61 \pm 2.06$ \\
& & & \\
Storage at $60^{\circ} \mathrm{C}$ & & & $327.33 \pm 0.34$ \\
0 & $191.93 \pm 2.47$ & $264.54 \pm 6.59$ & $311.26 \pm 5.36$ \\
2 & $182.52 \pm 9.62$ & $246.58 \pm 2.61$ & $302.99 \pm 6.59$ \\
4 & $181.23 \pm 11.98$ & $239.46 \pm 10.26$ & $297.50 \pm 2.07$ \\
7 & $176.34 \pm 1.81$ & $215.75 \pm 3.92$ & $274.43 \pm 2.06$ \\
9 & $168.92 \pm 4.43$ & $180.13 \pm 0.43$ & $246.12 \pm 0.62$ \\
11 & $158.08 \pm 1.70$ & $178.47 \pm 5.74$ & $224.27 \pm 1.98$ \\
13 & $145.24 \pm 2.14$ & $149.81 \pm 5.34$ &
\end{tabular}

Table 2

Antioxidant activity of blackberry extract during storage

\begin{tabular}{cccc}
\hline \multirow{2}{*}{$\begin{array}{c}\text { Time } \\
\text { [days] }\end{array}$} & Antioxidant activity[mmol/L Trolox eq.] \\
\cline { 2 - 3 } & Blackberry & Blackberry + AA & Blackberry + BHA \\
\hline
\end{tabular}

Storage at room temperature

$\begin{array}{cccc}1 & 189.81 \pm 0.94 & 264.80 \pm 3.89 & 263.17 \pm 1.71 \\ 10 & 178.55 \pm 3.15 & 258.29 \pm 2.11 & 259.45 \pm 1.46 \\ 24 & 179.75 \pm 1.23 & 232.93 \pm 7.74 & 254.51 \pm 1.60 \\ 35 & 178.39 \pm 1.69 & 220.24 \pm 4.68 & 248.87 \pm 0.76 \\ 60 & 171.92 \pm 0.37 & 205.47 \pm 4.13 & 248.34 \pm 0.83 \\ 94 & 167.49 \pm 1.48 & 192.11 \pm 1.14 & 243.64 \pm 1.58 \\ 120 & 160.54 \pm 2.18 & 186.59 \pm 3.22 & 237.01 \pm 3.23 \\ 150 & 154.00 \pm 0.72 & 176.62 \pm 3.53 & 225.08 \pm 0.63\end{array}$

Storage at $60^{\circ} \mathrm{C}$

\begin{tabular}{cccc}
0 & $189.81 \pm 0.94$ & $264.80 \pm 3.89$ & $311.62 \pm 0.91$ \\
2 & $170.66 \pm 0.80$ & $254.73 \pm 13.38$ & $304.99 \pm 3.89$ \\
4 & $165.82 \pm 4.17$ & $246.71 \pm 1.76$ & $288.57 \pm 1.34$ \\
7 & $163.16 \pm 1.27$ & $217.85 \pm 2.42$ & $280.91 \pm 1.35$ \\
9 & $157.50 \pm 2.87$ & $208.31 \pm 5.05$ & $265.68 \pm 1.35$ \\
11 & $149.05 \pm 2.68$ & $196.78 \pm 2.12$ & $254.51 \pm 1.60$ \\
13 & $138.79 \pm 3.44$ & $180.51 \pm 3.48$ & $247.89 \pm 2.25$ \\
\hline
\end{tabular}

Table 3

Antioxidant activity of mulberry extract during storage

\begin{tabular}{crcc}
\hline \multirow{2}{*}{$\begin{array}{c}\text { Time } \\
\text { [days] }\end{array}$} & Mulberry & Mulberry + AA & Mulberry + BHA \\
\cline { 2 - 4 } & \multicolumn{3}{c}{ Antioxidant activity[mmol/L Trolox eq.] } \\
\hline \multirow{2}{*}{ Storage at room temperature } & & \\
1 & $93.80 \pm 1.75$ & $183.64 \pm 1.66$ & $169.23 \pm 4.57$ \\
9 & $92.54 \pm 2.57$ & $178.10 \pm 2.96$ & $168.47 \pm 2.85$ \\
20 & $93.04 \pm 0.42$ & $170.93 \pm 1.25$ & $165.95 \pm 1.83$ \\
\hline
\end{tabular}


Table 3 (continued)

\begin{tabular}{cccc}
\hline 35 & $92.09 \pm 1.55$ & $168.27 \pm 1.54$ & $162.68 \pm 1.07$ \\
60 & $88.54 \pm 1.02$ & $146.28 \pm 2.67$ & $150.37 \pm 3.41$ \\
90 & $84.20 \pm 3.33$ & $119.89 \pm 0.60$ & $142.76 \pm 1.22$ \\
120 & $79.09 \pm 2.40$ & $100.34 \pm 0.98$ & $140.80 \pm 0.62$ \\
150 & $74.20 \pm 2.95$ & $97.30 \pm 2.13$ & $133.46 \pm 1.93$ \\
Storage at $60^{\circ} \mathrm{C}$ & & & \\
0 & & & \\
2 & $83.80 \pm 1.75$ & $183.64 \pm 1.66$ & $241.44 \pm 3.27$ \\
4 & $82.88 \pm 3.31$ & $168.12 \pm 2.84$ & $196.82 \pm 1.90$ \\
7 & $77.09 \pm 4.22$ & $159.78 \pm 0.90$ & $188.64 \pm 0.68$ \\
9 & $75.62 \pm 2.14$ & $132.95 \pm 1.28$ & $162.58 \pm 3.56$ \\
11 & $72.14 \pm 3.28$ & $129.80 \pm 1.33$ & $162.68 \pm 1.07$ \\
13 & $68.33 \pm 1.77$ & $102.86 \pm 3.45$ & $157.71 \pm 2.19$ \\
\hline
\end{tabular}

\section{Table 4}

The values of rate constants and half-lives for anthocyanins degradation at room temperature

\begin{tabular}{lccc}
\hline Extract & $\mathbf{k}\left[\text { days }^{-1}\right]^{-3}$ & $\mathbf{t}_{\mathbf{1 / 2}}$ [days] & $\mathbf{R}^{\mathbf{2}}$ \\
\hline Bilberry & $2.999 \cdot 10^{-3}$ & 231.10 & 0.9879 \\
Bilberry + AA & $7.267 \cdot 10^{-3}$ & 95.38 & 0.9781 \\
Bilberry + BHA & $3.076 \cdot 10^{-3}$ & 225.33 & 0.9969 \\
\hline Blackberry & $9.665 \cdot 10^{-3}$ & 71.71 & 0.9942 \\
Blackberry + AA & $28.937 \cdot 10^{-3}$ & 23.95 & 0.9680 \\
Blackberry + BHA & $8.889 \cdot 10^{-3}$ & 77.98 & 0.9975 \\
\hline Mulberry & $13.217 \cdot 10^{-3}$ & 52.44 & 0.9903 \\
Mulberry + AA & $34.705 \cdot 10^{-3}$ & 19.97 & 0.9558 \\
Mulberry + BHA & $17.322 \cdot 10^{-3}$ & 40.02 & 0.9891 \\
\hline
\end{tabular}

Table 5

The values of rate constants and half-lives for anthocyanins degradation at $60^{\circ} \mathrm{C}$

\begin{tabular}{lccc}
\hline Extract & $\mathbf{k}\left[\right.$ days $^{-1}{ }^{\mathbf{1}}$ & $\mathbf{t}_{\mathbf{1} / \mathbf{2}}$ [days] & $\mathbf{R}^{\mathbf{2}}$ \\
\hline Bilberry & 0.263 & 2.64 & 0.9961 \\
Bilberry + AA & 0.329 & 2.11 & 0.9910 \\
Bilberry + BHA & 0.195 & 3.56 & 0.9966 \\
\hline Blackberry & 0.430 & 1.61 & 0.9905 \\
Blackberry + AA & 0.404 & 1.71 & 0.9986 \\
Blackberry + BHA & 0.355 & 1.95 & 0.9892 \\
\hline Mulberry & 0.404 & 1.71 & 0.9735 \\
Mulberry + AA & 0.447 & 1.55 & 0.9493 \\
Mulberry + BHA & 0.336 & 2.07 & 0.9457 \\
\hline
\end{tabular}

\section{CONCLUSIONS}

The present study revealed that high temperatures and long storage periods affect the anthocyanins content in crude extracts. The obtained results indicate that the monomeric anthocyanins degradation followed first-order reaction kinetics. As expected, a very fast degrada- tion occurred at high temperature. During storage at room temperature, anthocyanins showed a better stability. The untreated fruits extracts present a good stability. Generally, the anthocyanins in ascorbic acid-treated extracts showed a faster degradation. The values obtained for kinetic parameters during storage at room temperature clearly show the negative effect of ascorbic acid on 
anthocyanin stability. The addition of BHA was found to have no significant influence on anthocyanins concentrations for bilberry and blackberry extracts; for mulberry extract was observed a more pronounced negative effect. During storage, antioxidant activity shows only a slight decrease compared with anthocyanins content. This may be possible if formed degradation products have also antioxidant properties.

\section{REFERENCES}

1. J. He and M. M. Giusti, Annu. Rev. Food Sci. Technol. 2010, 1, 163-187.

2. R. E. Wrolstad, J. Food Sci. 2004, 69, C419-C425.

3. L. S. Wang and G. D. Stoner, Cancer Lett. 2008, 269, 281-290.

4. D. Ghosh and T. Konishi, Asia Pac. J. Clin. Nutr. 2007, $16,200-208$

5. H. Guo and W. Ling, Rev. Endocr. Metab. Disord. 2015, 16, 1-13.

6. T. C. Wallace, $A d v$. Nutr. 2011, 2, 1-7.

7. T. C. Wallace, M. Slavin and C. L. Frankenfeld, Nutrients 2016, 8, 32-44.

8. A. Castañeda-Ovando, M. Pacheco-Hernández, M. E. Páez-Hernández, J. A. Rodríguez and C. A. Galán-Vidal, Food Chem. 2009, 113, 859-871.
9. A. Patras, N. P. Brunton, C. O'Donnell and B. K. Tiwari, Trends Food Sci. Technol. 2010, 21, 3-11.

10. İ. Gülçin, Arch. Toxicol. 2012, 86, 345-391.

11. V. A. Vaclavik and E. W. Christian, "Food additives", in V. A. Vaclavik and E. W. Christian (Ed.): "Essentials of Food Science", $4^{\text {th }}$ Edition, Springer Science + Business Media, New York, 2014, p. 343-366.

12. M. Carocho and I. C. F. R. Ferreira, Food Chem. Toxicol. 2013, 51, 15-25.

13. M. M. Giusti and R. E. Wrolstad, "Unit F1.2. Anthocyanins. Characterization and Measurement of Anthocyanins by UV-Visible Spectroscopy", in "Current Protocols in Food Analytical Chemistry", John Wiley \& Sons, New York, 2001, p. F1.2.1-F1.2.13.

14. I. F. F. Benzie and J. J. Strain, Anal. Biochem. 1996, 239, 70-76.

15. M. S. Poei-Langston and R. E. Wrolstad, J. Food Sci. 1981, 46, 1218-1236.

16. V. V. De Rosso and A. Z. Mercadante, Food Chem. 2007, 103, 935-943.

17. M. E. West and L. J. Mauer, J. Agric. Food Chem. 2013, $61,4169-4179$.

18. M. N. Ştefănuț, A. Căta, R. Pop, C. Tănasie, B. Pintea and I. David, J. Agroalim. Process. Technol. 2010, 16, 36-40.

19. W.-D. Wang and S-Y. Xu, J. Food Eng. 2007, 82, 271275.

20. Ş. Kara and E. A. Erçelebi, J. Food Eng. 2013, 116, 541547. 
